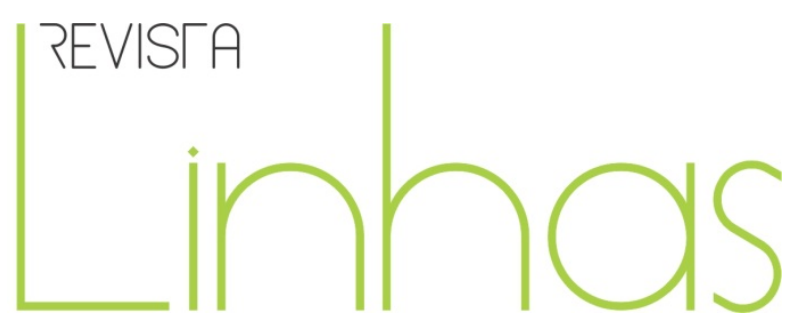

\title{
A montagem da escolarização: discutindo conceitos e modelos para entender a produção histórica da escola moderna
}

\begin{abstract}
Resumo
Vários conceitos têm sido propostos para entender a especificidade da educação e da sua persistência no tempo e no espaço, apesar de várias tentativas para reformá-la. Neste artigo, a autora analisa mais de perto os conceitos de "gramática da escolarização", "forma escolar" e "cultura escolar". Esses conceitos também têm sido usados para tratar da expansão global da escolarização e da adoção de estruturas e visões semelhantes, num processo coincidente com o de ocidentalização e do colonialismo. A autora lê os três juntos e analisa com certo detalhe o que eles dizem sobre a escolarização, bem como alguns de seus pontos cegos. Ela, então, apresenta duas alternativas para o que percebe serem suas limitações: em primeiro lugar, uma abordagem histórica e antropológica para a cultura escolar e, em segundo, o conceito de redes e montagens de Bruno Latour. Embora as duas não sejam exclusivas uma da outra, elas tendem a crescer em diferentes projetos intelectuais, que são aqui discutidos. Apesar de reconhecer que a teorização pode ser um projeto arriscado, a autora argumenta que os pesquisadores têm muito a ganhar ao navegar nestas águas turbulentas, produzindo uma teoria fundamentada e local que ilumine a "mais do que uma, menos do que muitas" configurações da escolarização.
\end{abstract}

Palavras-chave: Teorias da escolarização; Forma escolar; Gramática escolar; Cultura escolar; Teoria do ator em rede.

\author{
Inés Dussel \\ Departamento de Investigações \\ Educativas do CINVESTAV-IPN \\ México \\ idussel@gmail.com
}

\section{Para citar este artigo: \\ DUSSEL, Inés. A montagem da escolarização: discutindo conceitos e modelos para entender a produção histórica da escola moderna. Revista Linhas, Florianópolis, v. 15, n. 28, p. 250-278, jan./jun. 2014. Título original: The Assembling of Schooling: discussing concepts and models for understanding the historical production of modern schooling. Traduzido por Fernando Coelho, com revisão técnica de Vera Lucia Gaspar da Silva e Geovana Mendonça Lunardi Mendes.}

DOI: $10.5965 / 1984723815282014250$

http://dx.doi.org/10.5965/1984723815282014250 


\title{
The Assembling of Schooling: discussing concepts and models for understanding the historical production of modern schooling
}

\begin{abstract}
Several notions have been proposed to understand the specificity of schooling and its persistence across time and space, despite several attempts to reform it. In this article, the author analyses more closely the notions of the "grammar of schooling", forme scolaire, and "school organizational culture". These notions have also been used to address the global expansion of schooling and the adoption of similar structures and visions, in a process coterminous with westernization and colonialism. The author reads the three of them together and analyses with some detail what they say about schooling as well as some of their blind spots. She then presents two alternatives to what she perceives to be their shortcomings: first, a historical and anthropological approach to school culture; and second, Bruno Latour's notion of networks and assemblages. While the two of them are not exclusive of each other, they have tended to grow different intellectual projects that are discussed here. While acknowledging that theorizing might be a risky project, the author argues that researchers have a lot to gain from navigating these turbulent waters, producing a grounded, local theory that illuminates the 'more than one, less than many' configurations of schooling.
\end{abstract}

Keywords: Theories of schooling; School form; Grammar of schooling; School culture; Actor-network theory. 
A pesquisa educacional precisa de uma teoria da escolarização? Esta é uma questão ambiciosa, que provavelmente é melhor deixar aberta, como se estivesse sem resposta. Mas "sem resposta" não significa rejeitada: a pesquisa utiliza, consciente ou inconscientemente, conceitos e teorias, que no campo educacional, na maioria das vezes, passam por conceitos naturais, familiares. Além disso, em um momento de declínio das grandes narrativas e teorias, os pesquisadores geralmente limitam-se a casos empíricos e descrições locais, vistos como refúgios seguros no turbilhão teórico.

Este texto tem origem em um simpósio ${ }^{1}$ realizado em um encontro de história da educação, que foi contra essa tendência e foi criado para discutir a teoria e os conceitos para entender a escolarização. Um grupo de estudiosos queria investigar as possibilidades e limites abertos por conceitos como a gramática da escolarização, a forma escolar e cultura escolar. Esses conceitos têm sido propostos para explicar a persistência de formas particulares de pensamento e de organização das escolas, apesar de várias tentativas de reforma. Eles também têm sido utilizados para tratar a expansão global da escolarização e da adoção de estruturas e visões semelhantes, em um processo coincidente com o de ocidentalização e colonialismo (ver Ramírez, 2003 e também a contribuição a esta questão de Depaepe \& Hulstaert, 2013).

Nestas páginas, eu gostaria de participar deste projeto discutindo as noções de "gramática da escolarização" (Tyack \& Cuban, 1995) e "forma escolar" (Vincent et al, 1994), acrescentando o conceito de “cultura escolar" (Prosser, 1999; mas também Julia, 1995). Gostaria de ler os três juntos e analisar de perto o que dizem sobre a escolarização, bem como alguns de seus pontos cegos. Vou então apresentar duas alternativas para o que considero serem suas limitações: primeiro, uma abordagem histórica e antropológica de cultura escolar; e, segundo, a conceitualização derivada da teoria do ator-rede de Bruno Latour e seu conceito de redes e montagens. Embora as duas não sejam exclusivas

\footnotetext{
${ }^{1}$ O Simpósio Grammar of Schooling, forme scolaire, modèle scolaire. Concepts and Models Describing Mass Scolarization and the Teacher State - 19th 20th Centuries foi organizado por Rita Hofstetter e Bernard Schneuwly na Conferência Internacional Permanente para a História da Educação (ISCHE 33), San Luis Potosí, México, 2011. O grupo, posteriormente, se encontrou na reunião da Associação Europeia de Pesquisas Educacionais em Cádiz, Espanha, em 2012. A autora agradece os comentários feitos à uma primeira versão desse texto pelos professores Diana Vidal (USP), Marcelo Caruso (Humboldt Universität) e Elsie Rockwell (DIE-CINVESTAV).
} 
uma da outra, elas tendem a crescer em diferentes projetos intelectuais. A teorização pode ser arriscada, mas eu gostaria de argumentar que os pesquisadores têm muito a ganhar ao navegar nestas águas turbulentas, e muito a perder se eles simplesmente aceitarem as interpretações que passaram por inquestionáveis.

O ponto de partida é que os conceitos de gramática da escolarização, forma escolar e cultura escolar são noções importantes que inspiraram obras significativas na história da educação e a discussão das políticas educacionais (ver Chervel, 1998²; Faria Filho et al, 2004; Vidal, 2005; Lahire, 2008). Em alguns países da América Latina, o conceito de "forma escolar", em particular, está sendo utilizado em estudos políticos e sociológicos sobre a escolarização, e está servindo para mudanças de política nos regimes acadêmicos das escolas (ver Baquero et al, 2007; Martinis \& Stevenazzi, 2008; Southwell, 2011, entre muitos outros). Todos esses conceitos foram produtivos na geração de teses sobre a escolarização e também de estratégias de mudanças educacionais.

Ao selecionar esses três conceitos como a base de minha discussão, estou ciente de que existem outros caminhos que não seguirei. Por exemplo, o trabalho seminal de Hamilton, Towards a Theory of Schooling (1989), propõe uma teoria historicamente fundamentada que vê a escolarização como resultado de dinâmicas sociais, pedagógicas e epistemológicas, a qual aponta para as conexões e continuidades entre as pedagogias dos séculos XVI e XVIII e a escolarização em massa do século XIX. A discussão provocadora de Hunter das escolas como uma tecnologia socialmente improvisada feita de pedagogias e organizações disponíveis (Hunter, 1994) fornece outra hipótese rica e sugestiva, que foi acolhida por muitos estudiosos (entre eles, Wexler, 1994/1995). No entanto, eles não tiveram a mesma quantidade de repercussões na pesquisa educacional como os conceitos de gramática, forma ou de cultura escolar. Isso pode estar relacionado

\footnotetext{
${ }^{2}$ Chervel tinha realmente teorizado sobre disciplinas escolares e cultura escolar antes de 1993, quando Julia falou pela primeira vez sobre a cultura escolar em uma reunião da ISCHE, o que é considerado o início de seu sucesso atual (ver Faria Filho et al, 2004). Esta conceptualização implicou um debate com a noção de "transposição didática", que enfatizou a dependência do currículo escolar aos campos disciplinares. Em vez disso, Chervel apontou para a especificidade do conteúdo escolar e para o processo de produção de um determinado conjunto de regras e práticas, que alguns anos depois Julia enquadrou como "cultura escolar" (cf. Chervel, 1991).
} 
ao fato de que estes últimos tenham oferecido simples metáforas para falar de questões complexas, como será discutido abaixo.

A intenção deste artigo, no entanto, não é estudar o impacto ou a popularidade desses conceitos, mas discutir o que eles nos ajudam a ver e o que nos impedem de ver. Não farei uma réplica histórica de seus argumentos, nem julgarei qual está "mais perto" de seu referente. $O$ interesse é analisar as metáforas particulares em que esses conceitos são fundamentados e que têm o seu próprio peso ${ }^{3}$. Além disso, estou interessada em analisar como essas “várias 'ordens' de objetos, temas, campos semelhantes” reforçam interpretações diferentes e impõem diferentes "silêncios" (ver Mol \& Law, 2002, p. 7). Quais são os processos e as imagens "postos em primeiro plano aqui, em segundo plano lá” (p. 9) por essas metáforas? Como eles dão forma e produzem conhecimento sobre a escolarização? E de que outros aspectos podem revestir-se conceitos mais complexos e variados de escolarização?

\section{Gramática, Forma, Cultura Organizacional: lidando com estruturas e padrões}

Como se disse antes, os conceitos de "gramática", "forma" e "cultura organizacional" têm sido conceitos poderosos e produtivos para os pesquisadores educacionais. Curiosamente, os três conceitos surgiram mais ou menos ao mesmo tempo, entre os anos 1980 e início dos anos 1990.

Por que essa coincidência? Como Elkins diz: "fontes interpretativas são escolhidas em parte porque elas estão no ar" (2007, p. 482). Naquela época, as mudanças nos estudos educacionais passaram de compreender e promover a mudança para analisar por que as escolas eram tão difíceis de transformar. Após o otimismo generalizado do pósguerra, o fracasso das reformas, como colocaram Tyack e Cuban (1995), requereu uma conceituação mais ampla que ainda não estava disponível. Além disso, as fronteiras nacionais, que foram tidas como variáveis significativas, tornaram-se menos importantes do que os processos globais e as características comuns. Um eco dessas "estruturas de

\footnotetext{
${ }^{3}$ Metáforas, como Lakoff e Johnson (1980) defendem, possuem a capacidade de organizar programas de pesquisa em certas direções e podem se tornar profecias autorrealizáveis.
} 
sentimentos" (Williams, 1977) é encontrado em um comentário escrito por Basil Bernstein: "Quando eu li (mas mais frequentemente quando viajei) ocorreu-me que o que temos de explicar sobre os sistemas educacionais, as práticas de ensino, não é quão diferentes eles são, mas a sua semelhança impressionante" (Bernstein, 1990, p. 169). Estes novos conceitos foram destinados a explicar a persistência da escolarização através do tempo e do espaço. Mas os três conceitos prosperaram e seguiram diferentes tradições intelectuais e problemáticas educacionais que vale a pena olhar mais de perto.

Das três metáforas, o argumento sobre a "gramática da escolarização" é provavelmente o mais conhecido. O conceito de Tyack e Cuban (1995) é mais um argumento histórico do que um conceito teórico, e surgiu a partir da experiência norteamericana/EUA com a escolarização, uma distinção que nem sempre tem sido feita quando "aplicada" a outras localidades ${ }^{4}$. Essa é uma metáfora poderosa, mas suas consequências heurísticas têm ainda que ser exploradas de forma mais sistemática. Tyack e Cuban (1995) identificam quatro regras desta estrutura básica da escolarização que se mantiveram praticamente inalteradas, apesar de várias tentativas de reformá-las, e que são consideradas como o "núcleo" ou o coração das escolas. Estas quatro regras são: como as escolas dividem o tempo e o espaço; como classificam os alunos e os alocam em grupos (turmas graduadas); como dão forma a qual conhecimento que deve ser ensinado em disciplinas escolares; e como eles estruturam a promoção e o sistema de créditos dos alunos (sistema de unidades Carnegie). Como Depaepe et al (2000) enfatizam, essas regras apontam para a continuidade do quadro organizacional e estrutural da prática pedagógica, um quadro que tendeu a ser subestimado pelos debates curriculares e pedagógicos (p. 11).

Algumas observações podem ser feitas a este conceito. Em primeiro lugar, parece haver uma lacuna teórica. Apesar de usar uma palavra forte, carregada, como "gramática", e além do apelo óbvio à linguística e da referência às regras que geram discursos, Tyack e Cuban não fornecem aos seus leitores uma discussão aprofundada sobre o que significa considerar a escolarização em termos de "gramática". Por exemplo,

\footnotetext{
${ }^{4}$ Como exemplo da discussão que poderia ser feita sobre a viagem de conceitos e ideias, ver a obra editada por Tom Popkewitz sobre a apropriação distinta das obras de John Dewey em diferentes países (ver Popkewitz, 2005).
} 
algumas das questões que surgem caso a gramática da escolarização seja considerada como um conceito teórico são: que tipo de gramática seria - tradicional, gerativa, funcional? Ou seja, seria centrada na semântica, na sintaxe ou na pragmática das asserções e práticas da escolarização? Além disso, o que é deixado de fora se a escola é considerada como gerada apenas pelas regras? E o que dizer sobre aquelas práticas soltas que não "se encaixam na regra"? São esses casos marginais sem importância que não têm consequências para a experiência da escolarização?

Uma contraposição interessante pode ser feita com o Dictionnaire de Pédagogie, dirigido por Ferdinand Buisson, que em 1887 transcreveu no seu verbete "Escolas primárias" um discurso proferido por Jules Ferry em 1880, o então Ministro da Instrução Pública da França, aos professores reunidos na Sorbonne: "Para o tradicional e fundamental ensino da leitura, escrita e aritmética, deve-se acrescentar uma série de acessórios que poderiam parecer à primeira vista um pouco exagerados, estudos que poderiam ser considerados muito variados: aulas com objetos, desenho, aulas de história natural, museus escolares, ginásio, viagens de campo, trabalhos manuais, coral, canto, que irão penetrar com a sua implementação. Por que esses acessórios? Porque eles são para nós a coisa mais importante, porque eles fazem os alunos amar a escola, ... porque eles fazem da escola uma escola de educação liberal" (citado em Buisson, 1887; grifo meu). Para Ferry e Buisson, a escolarização inclui muito mais do que uma lista de conteúdos; o que era importante era como essas matérias e detalhes moldaram a educação das sensibilidades, a ligação da comunidade, o conhecimento corporal. Práticas que poderiam não ser percebidas como centrais, e no entanto foram concebidas como tais durante a organização dos sistemas nacionais de ensino.

A minha segunda observação é que, apesar de essa conceituação ser um pouco leve, o conceito parece ter inspirado uma boa pesquisa, mas também pode produzir novas questões de pesquisa que ainda estão por ser exploradas. Por exemplo, a centralidade dessas regras para a compreensão da escolarização precisa ser examinada nos Estados Unidos, bem como alhures. Tal questão poderia lidar com a forma como o modelo da escola graduada se espalha ao redor do mundo, juntamente com outra pergunta sobre como e por que o sistema de unidades Carnegie não se espalhou tão 
rapidamente e tão eficazmente em outros lugares como a escola graduada, e por que outras formas de promoção e de créditos prevaleceram em diferentes sistemas escolares nacionais. Além disso, pensando na organização do tempo e do espaço, estes elementos têm sido realmente tão persistentes e invariáveis como Tyack e Cuban defendem? Como foram definidos os horários - os calendários diários, semanais e anuais - nos diferentes sistemas educacionais nacionais e locais, e como mudaram nos últimos 150 anos? São ainda os mesmos?

Ao responder a esse tipo de pergunta, os pesquisadores provavelmente buscariam argumentos mais complexos sobre a escolarização moderna, a sua disseminação junto dos movimentos das potências imperiais e da ocidentalização, e das negociações que se realizaram com os agentes e contextos locais (suas traduções para uma gramática local, para manter o termo). Eles também prestariam atenção ao ditado de Arjun Appadurai segundo o qual "se a genealogia das formas culturais é sobre a sua circulação através das regiões, a história dessas formas é sobre a sua contínua domesticação em práticas locais" (Appadurai, 1996, p. 17). Esta dimensão tem sido negligenciada por aqueles que usam o conceito de "gramática da escolarização".

O segundo conceito que vou considerar neste texto é claramente orientado pela teoria. O historiador francês da educação Guy Vincent afirma que a escola deve ser entendida como uma forma, tomando o conceito de Gestalt da forma como uma marca na consciência. A característica básica da forma escolar é sua confiança na escrita - o que poderia ser chamado de sua qualidade de escrita / escritural. Juntamente com Thin e Lahire, ele afirma que a escola é definida pela "constituição de um universo separado para as crianças; a importância das regras para a aprendizagem; a organização racional do tempo; a multiplicação e a repetição de exercícios, cuja única função é a de aprender e aprender de acordo com regras, ou, melhor dito, tendo como fim os seus próprios objetivos" (Vincent et al, 1994, p. 9). A forma escolar é uma noção que aponta para a especificidade dos modos escolarizados de socialização (Lahire, 2008, p. 230).

\footnotetext{
${ }^{5}$ De fato, o estudo de Compère sobre horário escolar na Europa mostra que houve mudanças significativas através do tempo e do espaço, e variados desafios para a atual organização do tempo (Compère, 1997).
} 
Numa inspiração similar ao conceito de gramática, o conceito de forma escolar também salienta que as escolas partilham uma configuração básica, embora, no caso da forma escolar, isto seja pensado como uma estrutura, com conexões com a sociologia estruturalista. Como observado por Vidal (2005), o conceito de Vincent et al não pode ser compreendido separadamente dos debates teóricos sociológicos franceses sobre a escolarização, ou dos estudos pedagógicos das disciplinas e currículos escolares, como de Chervel $^{6}$. A estrutura ou o sistema se impõe aos indivíduos; os agentes executam determinadas ações, porque a forma faz com que eles efetuem isto. A ênfase é colocada em uma organização coerente, em salientar princípios que produzem hierarquias e organizam o espaço e o tempo.

Além de sua qualidade sistemática, outra distinção entre o conceito de forma escolar e da gramática da escolarização é feita sobretudo pela escrita - ou seja, pelo poder da escrita de organizar a cultura escolar - o que, por outro lado, provavelmente diz mais sobre as escolas francesas do que sobre a escolarização em geral (ver Chartier, 2007). ${ }^{7}$ O conceito de forma também tem uma qualidade visual, uma característica importante já observada por Bernstein, e à qual voltarei mais tarde.

O terceiro conceito que eu gostaria de rever é o de cultura escolar. Ele foi muito mais livremente utilizado em pesquisas e, portanto, merece uma consideração diferente. É um conceito que não foi cunhado por um único autor ou trabalho como os anteriores foram.

Uma das abordagens mais importantes e populares para o conceito de cultura escolar identificou-o com a cultura organizacional da escolarização. Nesta linha, a revisão de pesquisa de Jon Prosser é uma referência fundamental. Segundo ele, a tradição angloamericana começou a pensar sobre a dimensão cultural do ensino nas décadas de 1960 e 1970, como uma forma de analisar o clima organizacional das instituições (Prosser, 1999, p. 2). Esta linha de pesquisa ganhou apoio com a agitação da pesquisa da eficiência da

\footnotetext{
${ }^{6}$ Ver nota 3.

${ }^{7}$ Em um ensaio muito sugestivo, a historiadora mexicana Elsie Rockwell reflete sobre sua experiência de ser uma etnógrafa em escolas francesas e tentar entender a hierarquia das práticas de escrita (ver Rockwell, 2012). Infelizmente, esse movimento de desnaturalização do familiar e o de voltar a vista do etnógrafo para as culturas metropolitanas não encontrou muitos seguidores na pesquisa educacional.
} 
escola no fim da década de 1970. A eficiência da escola e a melhoria da pesquisa da escola alegaram que a atmosfera geral ou ethos de uma instituição tiveram um grande impacto sobre o ensino e a aprendizagem (Prosser, 1999, p. 3). Jon Prosser diz que "no início de 1980 , os termos ethos da escola, clima, cultura, atmosfera e tom eram onipresentes" (Prosser, 1999, p. 3). Sociólogos qualitativos e estudos culturais também ajudaram na disseminação do conceito, tornando mais difícil a concordância sobre seus traços centrais e limites.

Apesar de sua amplitude, Prosser oferece uma definição que pretende captar a gama de interesses e linhas que utilizam esse conceito:
“A cultura escolar é uma força invisível e não observável atrás das atividades escolares, um tema unificador que fornece significado, direção e mobilização para os membros da escola. Tem tanto representação concreta na forma de artefatos e normas de comportamento, quanto jargões, metáforas e rituais implicitamente mantidos" (Prosser, 1999, p. 14).

Na mesma linha Louise Stoll argumenta que a cultura escolar é “o nível mais profundo de pressupostos básicos e crenças que são compartilhados por membros de uma organização, que operam de forma inconsciente, e que definem em uma forma básica "aceita sem mais" de uma visão da organização de si mesma e de seus ambientes" (Schein, citado por Stoll, 1999, p. 33).

Um dos textos mais importantes para o estudo comparado dos sistemas educacionais segue esta vertente de conceituação. Em Culture and Pedagogy, o grande livro escrito por Robin Alexander para discutir o que os sistemas de ensino e formas de ensino têm em comum e o que não têm, a cultura figura, em primeiro lugar, como a “cultura nacional”. A cultura é identificada como uma influência homogênea que molda a pedagogia e a organização escolar em cada um dos cinco países que ele estudou (o Reino Unido, os Estados Unidos, a França, a Índia e a Rússia). Mas Alexander também afirma que "as escolas e as salas de aula são microculturas com seu próprio direito. Elas mediam mensagens e exigências que vêm de cima e acrescentam alguns dos seus próprios. E cada nível é o seu próprio tipo de janela na cultura maior" (Alexander, 2000, p. 531). A cultura está em toda parte: "nós comparamos entre culturas para iluminar e entender (crença de Sadler), para confirmar nossas práticas existentes ou para mudá-las" (Alexander, 2000, p. 
564). A cultura é um conjunto de crenças, o cimento invisível que nos une e que nos dá traços distintivos. Há uma suposição de que a cultura funcione como e em uma camada mais profunda, determinando nossas ações enquanto não somos conscientes delas, agindo como uma força homogênea.

Para resumir esta primeira parte, eu diria que, considerados em conjunto, os três conceitos compartilham alguns elementos que creio que se tornaram limitações para uma compreensão mais ampla da produção sobre a escolarização:

1. Eles contam com um conceito de escolarização como uma experiência coerente e unificada que pode ser explicada por um único e homogêneo "princípio de ordenação"8 que jaz sob práticas cotidianas. A escola é considerada "como um sistema amarrado, um recipiente de processos em sala de aula e textos curriculares, uma concha institucional esperando para ser preenchida pelas ações de professores, alunos, administradores" (Nespor, 1997, p. xi).

2. Eles tendem a se concentrar na vida simbólica das escolas e suas razões, e a negligenciar o peso do material cultural da escolarização, o como e o quando da escolarização, e as disposições dos corpos no espaço público (o que Eugenia Roldán [2012] chamou de "coreografias escolares").

3. Eles tendem a considerar-se como conceitos universais que podem ser aplicados a diferentes experiências locais e nacionais. Os conceitos de gramática da escolarização e de forma escolar enfatizam a produção e a circulação de ideias e padrões institucionais, mas tendem a apagar as localidades de onde surgiram, como foi observado no caso do papel da escrita em escolas francesas, mas não necessariamente em outros sistemas escolares, ou da resistência da unidade de Carnegie, mal sucedido e praticamente desconhecido em outros países. O conceito de cultura organizacional, por outro lado, tem implicado, pelo menos em alguns trabalhos, como de Alexander (2000), a análise das diferenças nacionais; contudo, na maior parte do tempo, o quadro de organização é igualado ao processo de modernização e burocratização, e, portanto, é naturalizado como uma experiência universal.

\footnotetext{
${ }^{8}$ Popkewitz (2008) relaciona os princípios de ordenação da pedagogia às suas raízes calvinistas, também se referindo à obra de David Hamilton mencionada anteriormente.
} 
Multiplicidade em toda parte: visões históricas e antropológicas da cultura escolar

Um desafio importante para estas limitações foi lançado por uma abordagem diferente para a cultura escolar, alimentado por historiadores e antropólogos. Um importante ponto de referência desta perspectiva foi o influente artigo publicado em Paedagogica Historica em 1995 pelo historiador francês Dominique Julia. No campo da história da educação, a reflexão de Julia foi recebida como uma noção que abre espaço para a multiplicidade e a criatividade da vida cotidiana, e para se preocupar com estruturas pesadas e as forças reprodutivas. Fundamentada nas visões de cultura de Michel de Certeau e Roger Chartier, o conceito de Julia inclui espaços, atores, conhecimentos, normas, comportamentos; ele aponta para o "conjunto de práticas correlatas, construídas dentro das instituições educacionais ao longo do tempo, que permitem disciplinas de ensino e comportamentos inclusivos na formação de sujeitos no processo de socialização" (Julia, 1995, p. x). Este autor afirma que as culturas têm uma vida prática, diária, que precisa ser investigada, e este recurso para o nível de prática tem, ao fim, o efeito, de acordo com Rockwell, de borrar a sua definição inicial centrada em normas (2009, p. 159). A qualidade dinâmica e histórica da cultura rompe com a noção funcionalista de cultura como uma entidade homogênea.

A cultura escolar abriu caminho para uma noção de culturas escolares plurais. $O$ historiador espanhol da educação Escolano Benito (2000) argumenta que existem vários tipos de culturas escolares - a cultura dos administradores e burocratas (cultura política), a cultura de praticantes (empírico-prática), e a cultura de especialistas e acadêmicos (cultura científica): "Cada uma dessas culturas foi desenvolvida de acordo com lógicas próprias e deu lugar a uma tradição particular" (p. 203). Viñao Frago (2002) também introduziu a ideia de culturas institucionais - de culturas que foram produzidas por instituições particulares, e que são o produto de outros tipos de alinhamento (instituições públicas/privadas, primárias/secundárias/terciárias, entre outras). As culturas não são apenas as de escolas primárias ou secundárias, ou prerrogativas dos professores ou reformadores, elas também são produzidas por cada escola (ver Faria Filho et al, 2004). 
Outra característica da abordagem histórico-antropológica de cultura escolar é que ela salienta que as escolas são constituídas tanto por normas quanto por práticas. Isso abre uma interessante série de derivações. Como sublinha Rockwell, ela ajuda a evitar a ilusão de uma "onipotência normativa” da escolarização: as escolas prescrevem certos comportamentos, organizam o tempo, procuram regular o intercâmbio entre as matérias e produzem identidades, mas sua ação é múltipla e imprevisível devido às complexidades da experiência escolar. Mesmo que se estude a história do ensino da escrita, uma área que é mais facilmente regulada e controlada do que outras práticas por causa de sua separação clara e arbitrariedade em relação às atividades diárias, nunca se poderia dizer que a ação da escola foi homogênea e eficaz (Vidal, 2005). Mas incluir a norma juntamente com as práticas é útil para lembrar que os quadros regulatórios induzem comportamentos e fornecem orientações, e que as normas não são neutras em relação ao que acontece nas escolas. Como Rockwell coloca, há tanto entrelaçamento quanto há "desvinculação" nas relações entre as normas e práticas na vida escolar (Rockwell, 2009, p 161).

Nesta linha de investigação, um livro importante é o que trata da história de como a leitura e a escrita foram ensinadas (2007) de Anne-Marie Chartier. Ela utiliza a cultura e a cultura escolar em toda a sua obra, e entende a cultura como um conjunto de práticas mais do que como normas. Curiosamente, define cultura escolar como a autoridade cultural das escolas, o seu conteúdo, o currículo e o conhecimento que é privilegiado, e se propõe a estudar as suas mudanças históricas. O trabalho de transformar continuamente a cultura escolar legítima é o que, seguindo Certeau, ela chama de "operação historiográfica", uma reescrita da história. Citarei um parágrafo longo para mostrar seu argumento sobre a mudança cultural:

A instituição da escolarização não deixa de revisar um corpus de referência através do qual, implicitamente, chega em um acordo com o presente. No entanto, como é sempre mais difícil somar do que subtrair, ... a última versão oficial não apaga as anteriores. A cultura legitimada pela escolarização torna-se um repertório de orientações tão amplo que cada professor tem que pesquisar e escolher tudo que ele quer fazer ou apenas o que ele pode fazer. Diante de um assunto demasiadamente extenso, todo mundo corre o risco de fazer escolhas subjetivas (o que sempre foi feito), escolhas locais (o que funciona com essas crianças, 
nesse meio), instáveis (no próximo ano vou tentar algo diferente). Em suma, a cultura escolar é cada vez mais semelhante à cultura de massa [la culture de masse]. (Chartier, 2007, p. 235, tradução minha [para o inglês])

Em sua opinião, a "forma escolar", os limites das escolas e as regras para definir e legitimar um conhecimento específico ou a relação com o conhecimento, estão sendo afrouxados pelas mídias culturais massivas da contemporaneidade, e não podem mais operar como a "máquina básica" que define o que é ensinado nas escolas e como é ensinado. A cultura escolar legítima não é mais a cultura legitimada pela sociedade, como costumava ser.

Outra contribuição importante da conceituação histórico-antropológica de cultura escolar pode ser encontrada na vertente de pesquisa que destacou a relevância das culturas materiais de escolarização (Lawn \& Grosvenor, 2005). Esta abordagem pretende explicar "a relação entre a organização da escolarização de massas e sua manutenção por meio de tecnologias simples; as formas pelas quais as rotinas de aula e escola unem objetos e ações; a relação particular entre os inovadores e os artefatos, e a economia e o método de produção de artefatos escolares" (Lawn \& Grosvenor, 2005, p. 13). Além disso, o estudo brilhante de Anne-Marie Chartier de cadernos escolares é outro bom exemplo desta problematização das tecnologias escolares e das continuidades e mudanças nas práticas diárias (Chartier, 1999).

Numa linha diferente, mas relacionada, Symes e Meadmore (1999) pesquisaram o "parerga" das escolas, os eventos e artefatos que acontecem em suas superfícies e nas suas margens - viagens de campo, conversas e brincadeiras de corredor, práticas esportivas, rituais de entrada e de saída, uniformes escolares - que talvez pareçam inofensivos, mas acabam sendo muito importante para a vida das escolas, não apenas em termos de socialização e experiência de vida, mas também em termos de conhecimentos que produzem, do seu papel na produção de subjetividades, dos agrupamentos de pessoas, e das hierarquias que constroem.

Estes exemplos mostram que há obras importantes que estão sendo feitas e que têm tentado desafiar a noção de cultura como substrato unificado que permeia tudo e o ordena em torno de um principio singular, e, em vez disso, procura desvendar os "peças" 
múltiplas e complexas das quais é/são feito/s. No entanto, esta reconceitualização da cultura tem em sua maioria se mantido como um conceito heurístico, útil como uma categoria de pesquisa, mas nem sempre bem equipado para explicar a semelhança das paisagens escolares ou as tensões entre as continuidades e as mudanças nos sistemas educacionais.

\section{Da Multiplicidade às Redes: ampliando a escala e aproximando o olhar}

Na última seção deste artigo, gostaria de sugerir que há muito o que ganhar ao ler a obra de Latour e ao discutir como a sua compreensão da "montagem do social" pode ser relevante para o estudo da escolarização. Latour, sociólogo da ciência (uma atividade paradoxal, como ele mesmo diz, porque as ciências sociais e as ciências naturais têm sido exiladas umas da outras) e também historiador da tecnologia, deu contribuições substanciais aos campos das ciências sociais, dos estudos científicos e da filosofia (Latour et al, 2011), mas o impacto de sua posição teórica sobre a pesquisa educacional ainda é fragmentário (entre os notavelmente poucos, Nespor, 1997, 2002, 20069; Mukhopadhyay \& Sriprakash, 2011; Fenwick \& Edwards, 2012; e também Lawn \& Grosvenor, 2005, ecoam algumas dessas preocupações).

Do meu ponto de vista, sua teoria das interações entre atores, artefatos e redes (teoria do ator-rede, conhecida como ANT, actor-network theory) pode ser útil na análise da produção da escolarização moderna e na compreensão das suas complexidades. Ele afirma que o ponto de partida seria interrogar "o que é montado sob a égide de uma sociedade" (Latour, 2005, p . 21), e não aceitar simplesmente. A noção de "montagem" da organização de diferentes artefatos e assuntos é fundamental para a sua teoria social, e, nesse sentido, se aproxima da noção de lan Hunter de escolarização como uma tecnologia social improvisada (Hunter, 1994). Além disso, Latour afirma que "sempre que se deseja definir uma entidade (um agente, um atuante, um ator) ${ }^{10}$ é necessário implantar

\footnotetext{
9 Jan Nespor é um antropólogo educacional que trabalha na Universidade Estadual de Ohio e também pode ser incluído no grupo anterior. Mas, dada a sua conceptualização da escolarização na linha da ANT, escolhi discutir seu trabalho nesta seção.

${ }^{10}$ Um ator é um "alvo móvel de um vasto conjunto de entidades que se movem para ele" (Latour, 2005, p.
} 
seus atributos, ou seja, sua rede" (Latour, 2010, p. 4). Não se pode responder o que algo é sem olhar para a rede em que está inscrito, o conjunto de relações que definem seus atributos. É por isso que ele afirma que "rede é o conceito que ajuda a redistribuir e realocar a ação" (p. 5) a partir de um assunto ou uma entidade aparentemente consistente para a rede. A teoria $\mathrm{ANT}^{11}$ está preocupada com as conexões, as associações, as traduções e as transformações entre os atores ${ }^{12}$.

O método produz um impulso para ter uma visão míope, oligóptica (não panóptica), um olhar mais atento ao como, ao quando, às minúcias das conexões que compõem o social. Uma vez que se traçaram essas conexões e seus "traçadores" (todas as conexões deixam um rastro, por mais fraco ou difícil de ver), seus modos, seus mediadores, então se pode subir na escala, mas somente se as conexões mostram esse movimento. Por exemplo, um tema de pesquisa da ANT poderia ser carteiras escolares. Como elas foram colocadas nas escolas? Através de quais operações? Quem decidiu, como e quando, introduzir carteiras escolares em um sistema particular? Quais em particular? Como e quando esses modelos foram alterados? Quais os atores que tiveram voz: os políticos, os fabricantes, os inspetores escolares, as associações de pais, os alunos? Através de que meios de expressão: revistas, jornais, relatórios dos professores, boatos, pressões informais?

É através do rastreamento dessas ações que se pode decidir se a conexão foi efetivamente feita para outro conjunto de práticas que podem, então, ser chamadas de nível global ou nacional. Mas não se incluem uma na outra, como bonecas russas. Depende do ponto de vista e do controle das viagens e da mobilização das coisas. ${ }^{13} \mathrm{O}$

46). O fato de que a metáfora do ator vem do teatro sugere problemas semelhantes para a teoria social e para as artes cênicas. "Nunca é claro quem e o que está agindo quando agimos, já que um ator no palco nunca está sozinho ao agir" (p. 46). É um "grosso imbróglio" considerar os efeitos das reações do público, iluminação, encenador, roteiro, os personagens individuais etc. Como uma nota de rodapé na nota de rodapé, "imbróglio" é um termo que Latour usa de vez em quando para explicar a heterogeneidade. Por exemplo, em seu texto sobre Joliot, ele escreve: "este imbróglio de coisas e de pessoas - a nossa própria história" (Latour, 1995, p. 617).

${ }^{11}$ ANT é um acrônimo de Actor-Network-Theory, ou Teoria do Ator em Rede.

${ }^{12}$ Um ponto de vista diferente e sugestivo sobre redes é fornecido por Vidal (2005), através da noção de histórias conectadas. Vidal fundamenta sua teorização sobre a obra de Serge Gruzinski e sobre a história das redes e campos intelectuais. No entanto, os pressupostos teóricos são muito diferentes dos da teoria ANT.

${ }^{13}$ Coisas não são meros objetos. Latour toma a noção heideggeriana de Das Ding, a Coisa, como um 
global torna-se importante para o local, na medida em que é trazido à baila e mobilizado por alguns atores, e torna-se outro objeto nesta rede cujos efeitos não podem ser tidos como certos.

A esse respeito, outro elemento que julgo interessante nesta abordagem é que ele atribui "ação" para coisas que não são necessariamente humanas. Objetos são elementos da rede que interagem com outros elementos. Tomemos, por exemplo, as fotografias como objetos-atores em uma determinada rede. As fotos não são apenas pedaços de papel, mas são investidas de significados simbólicos que lhes dão outros atributos e acabam "fazendo coisas", produzindo ações em nós seres humanos (nós podemos chorar, rir, sorrir, tornar-nos nostálgicos ou felizes quando olhamos para fotos). Além disso, podem-se ver os artefatos escolares (obviamente imagens estão incluídas) como elementos que levam os agentes a fazer coisas em razão da sua inscrição em uma rede. Cadeiras e carteiras escolares condicionam a forma pela qual as pessoas podem sentar-se e mover-se em uma sala de aula; a organização do espaço físico fornece uma estrutura para a atenção humana, mas a arquitetura escolar ou o mobiliário escolar não pode fazêlo fora de uma rede - neste caso, fora de um conjunto de práticas discursivas, atores e artefatos que Ihes dão atributos particulares. Assim, enquanto a abordagem de Latour dialoga com a história e a antropologia, ela faz entrar em jogo outra dinâmica que não foi considerada por narrativas de pesquisa dominantes nesses campos.

Latour oferece o exemplo de uma sala de aula de universidade, que também poderia ser uma sala de aula qualquer. Ele diz:

Perscrute por um minuto tudo o que permite que você interaja com seus alunos sem ser perturbado pelo barulho da rua ou das pessoas do lado de fora, esperando no corredor para entrar em outra aula. Se você duvida do poder de transferência destes mediadores para fazer deste um lugar local, abra as portas e janelas e veja se pode ensinar alguma coisa assim. Se hesitar neste ponto, tente dar sua aula no meio de alguma exposição de arte com crianças gritando e alto-falantes vomitando música techno. O resultado é inevitável: se você não está completamente "enquadrado" por outras entidades postas silenciosamente em cena, nem você, nem seus alunos podem se concentrar por um minuto sobre o

ajuntamento, como uma questão que não está fora da mediação ou da política. Considere uma pedra como exemplo: uma pedra em um campo (objeto), ou uma pedra usada no discurso ou no campo de trabalho de geólogos, ambientalistas, mineradores ou arqueólogos (Coisa). 
que está sendo "localmente" alcançado. (Latour, 2005, p. 195; grifo do original)

No entanto, é notável que esta cena já esteja acontecendo em algumas salas de aula: salas de aula extremamente conectadas podem parecer cada vez mais como o ensino no corredor ou no refeitório de uma escola (na verdade, o ensino em / através do Facebook significa exatamente isto). Como isso vai mudar a interação em sala de aula? Que tipo de "intersubjetividade" afastada da "interobjetividade", para usar os conceitos de Latour, será implantada? As noções de forma escolar ou de gramática da escolarização parecem mal equipadas para lidar com esses tipos de transformações.

As perguntas sobre como, quando, quem, por que meios, não fazem Latour adotar o local de forma acrítica ou endossar o situacionismo numa celebração de uma recriação permanente do social. Na verdade, muito pelo contrário: ele defende o mesmo movimento de desmontagem e remontagem do global e do local. Ele não abandona a busca por explicações mais gerais. Ele nos adverte contra a permanência da pesquisa no nível de descrever a multiplicidade do social: numa frase brilhante, diz que "a multiplicidade não está em falta” no meio acadêmico de hoje (Latour, 2005, p. 190). “Limitar-se à [multiplicidade] também poderia significar que a tarefa política de montagem foi abandonada" (p. 190). Em vez disso, a teoria ANT está interessada em como o social (a escolarização, em nosso caso) foi e está sendo "produzida, montada, coletada ou mantida" (p.184), um movimento que nunca deixa de ocorrer, uma vez que o social está sendo permanentemente reconstituído.

Latour usa o conceito de cultura, mas ele diz:

“A cultura não age sorrateiramente por trás dos atores. Esta produção mais sublime é fabricada em locais e instituições específicas, seja nos escritórios bagunçados no andar superior da casa de Marshall Sahins no campus da Universidade de Chicago, seja na larga área dos arquivos mantidos no Museu Pitt Rivers em Oxford" (Latour de 2005, p. 175).

Esta conceituação é tão distante quanto possível do conceito de amálgama ou da camada mais profunda que dá forma à abordagem organizacional da cultura escolar. Mas ele também oferece uma qualidade material para a cultura que implica fundamentá-la em 
tradições historiográficas e antropológicas. "Nenhum conhecimento viaja sem os cientistas, os laboratórios, e as frágeis cadeias de referências" (Latour, 2005, p. 175). 0 estudo da materialidade das redes ajuda a explicar "por meio de quais veículos, quais traçados, quais trilhas, quais tipos de informações o mundo está sendo trazido para dentro desses lugares e, depois de ser transformados lá, está sendo bombeado de volta para fora de seus muros estreitos" (Latour, 2005, p. 179-180; grifo no original).

Latour propõe assim uma "cartografia plana”, uma espécie de mapeamento que não apela para forças ocultas, mas que tenta olhar para as ligações e transformações dentro de um determinado conjunto de práticas que, como disse antes, não pode ser limitado ou amarrado em um pacote singular. É preciso admitir que se inicia uma investigação sem saber completamente aonde e como a cadeia de associações nos levará. A escolarização foi o que prometeu ser? Foram os muros e cercas da escola o que imaginavam que seriam - os limites, as portas e as chaves de uma entidade limitada (Rockwell, 2005)? Estas e outras questões de pesquisa são pertinentes a este tipo de investigação.

O trabalho de montagem e de composição de elementos heterogêneos na rede está em algum lugar entre o modernismo e o pós-modernismo. Latour gosta do impulso deste último para criticar a ordem hierárquica e homogeneizadora em que a teoria moderna encerrou o social. Pensando sobre a escolarização, isso implicaria renunciar localizar um ponto de poder central e vertical nos sistemas escolares, e, em vez disto tentar entender a escolarização como um conjunto definido de relações, cuja configuração tem que ser entendida historicamente e localmente. Ao mesmo tempo, ele ainda apoia a busca de algum tipo de ordem e legibilidade, e, nesse aspecto, quer "reter... o sentimento do modernismo de clareza e ordem... libertado de sua conexão com a hierarquia e a verticalidade" (Latour, 2011, p. 5). O trabalho do sociólogo e do historiador é traçar essas associações, para historicizar e localizar essas relações, para dar alguma ordem e legibilidade a esta realidade opaca de interconexões.

Uma objeção que foi levantada à teoria ANT é que ela está mais interessada nos processos de tradução e mediação do que no que eles produzem. Para alguns críticos, isso significa que os objetos e os campos perdem sua especificidade. Se a pedagogia e a 
escolarização são historicamente montadas, isso significa que elas são iguais a qualquer outra forma cultural? Para Latour, é através da descrição histórica e etnográfica detalhada que um objeto ou uma coisa atinge à especificidade, e não a partir de uma ideia préconcebida que pode ser aplicada universalmente, ou de uma forma linear, à história. Como a escolarização foi definida como o tipo dominante de educação? Como os teóricos da educação foram equiparados aos da escolarização, como Hamilton afirmou (1989, p. 152)? Como foram as escolas nomeadas, por quem, e o que foi incluído e excluído dessa categorização? Como é que este nome foi mobilizado ao longo dos centros, em que série, através de quais os mediadores? Esse tipo de conceituação é relevante para a compreensão de processos antigos e atuais de escolarização, que continuam a definir hierarquias de conhecimento e autoridade de quem passa ou transmite este conhecimento (ver Gomes, 2004). As escolas, ou a prática pedagógica, não podem ser pensadas fora desses processos de tradução, mediação e reorganização de pessoas, eventos e objetos - ainda mais hoje, quando há tanta conversa sobre o "fim da escolarização" na era digital e com o nascimento de novos tipos de organizações educacionais (ver Selwyn, 2011).

Jan Nespor é um bom exemplo de um etnógrafo educacional que está trabalhando com a teoria de Latour e a ANT. Nespor propôs que os pesquisadores olhassem para as escolas, ou mesmo para casos particulares, "como uma intersecção em um espaço social, um nó em uma rede de práticas que se estendem em sistemas complexos que começam e terminam fora da escola" (Nespor, 1997, p. xiii). Nespor levanta uma questão interessante sobre por que as escolas podem ter a mesma aparência em algum nível, e isto está relacionado com a importância da visibilidade, de fazer as coisas visíveis de um modo particular, na escolarização. Nespor diz:

A instrução é o produto de múltiplos fluxos de atividade organizados em diferentes escalas espaciais e temporais, e para valer em outro lugar e mais tarde, o trabalho, as ideias, os eventos, e as pessoas precisam ser feitos visíveis em formas que podem mover-se nestas escalas. Membros de uma faculdade, por exemplo, têm que fazer seu ensino visível não só aos estudantes, mas de maneiras diferentes para os administradores dentro da universidade e burocratas que operam na escala do Estado. Administradores e burocratas precisam que o ensino seja visível em formas que lhes permitam pesar seus custos e valores em comparação 
com outras funções estatais e organizacionais. Os alunos precisam traduzir aulas, apresentações e laboratórios em formas visíveis que podem ser movimentadas e estudadas. Os professores têm que transformar aquele estudo (por exemplo, através de testes) em formas (por exemplo, notas) visíveis no sistema de contabilidade instrucional da universidade. Finalmente, as notas têm que oportunizar graus que fazem os alunos visíveis aos empregadores ou outras escolas. (Nespor, 2006, p. 2-3)

A questão da visibilidade, então, poderia ser um dos meios para seguir as conexões, as associações e as traduções que produzem a rede da escolarização - em outras palavras, que fazem as escolas se parecer, e aparecem como entidades similares em todo o mundo. Latour sugere que existem duas maneiras de olhar em teoria social: a oligóptica, o olhar de perto, o olhar que pode ver apenas algumas coisas, mas muito bem; e o panorama, a visão ampla que também fornece uma imagem que aparece como grande, como global, mas que precisa ser interrogada literalmente como uma imagem (“total coerência é o seu forte - e sua principal fragilidade”, diz Latour, 2005, p. 187).

Seriam as redes uma melhor metáfora para o estudo da escolarização do que a gramática, a forma ou a cultura? Em um texto recente, Latour fala sobre redes na era digital, quando é precisamente a metáfora da rede que foi colocada no centro das atenções e se tornou em um conceito todo-compreensivo. Latour diz:

O que eu sempre achei ótimo na metáfora da rede é que é então fácil de insistir na sua fragilidade, no lugar vazio que ela deixa em torno de si (uma rede é feita primeiramente de um espaço totalmente vazio), na subversão que introduz na noção de distância (os adjetivos 'perto' e 'longe' são feitos dependentes da presença de condutores, pontes e eixos), mas, acima de tudo, o que ela faz com a universalidade: a área "coberta" por qualquer rede é "universal", mas apenas enquanto e apenas onde há antenas suficientes, relés, repetidores, e assim por diante, para sustentar a ativação de qualquer trabalho. Graças à noção de redes, a universalidade é agora totalmente localizável. Na rede, é o trabalho que está se tornando o primeiro plano, e é por isso que alguns sugerem o uso da palavra worknet (rede de trabalho). (Latour, 2010, p. 6)

As características conceituais que Latour enfatiza na rede parecem particularmente fecundas para uma nova agenda de pesquisa, trazendo para o primeiro plano objetos e eventos que até agora permaneceram invisíveis na pesquisa educacional, 
a qual aceitou muitas coisas sem questionar. Em primeiro lugar, nesta conceitualização da rede existe uma consciência da fragilidade da rede, já que não há necessidade de relação entre os elementos, mas é o produto de uma montagem histórica de elementos distintos. Em segundo lugar, a imagem da rede torna visível o fato de que existem espaços vazios, incompletudes, entremeios, não encerramento de todo o conjunto. Em terceiro lugar, o conceito rompe com a noção de que tem que haver uma distância epistemológica: as coisas podem estar perto ou longe, dependendo de suas relações, e não se pode supor que seja apenas por sua localização em um espaço físico. Pode ser especialmente interessante considerar as escolas e a pedagogia como relações que são emolduradas pela distância, pela assimetria, por sua separação do mundo cotidiano, e por suas ligações com um mundo de conhecimento e de relações que é diferente do ambiente físico em que funcionam. A quarta característica também é relevante, e refere-se à discussão da universalidade. A rede pode ser universal apenas na medida em que é capaz de ativar uma rede. A universalidade não está embutida na rede; ela é produzida por forças históricas das quais é preciso dar conta.

A disseminação da forma escolar ou da instituição da escolarização pode ser analisada através destas lentes teóricas. Tanto quanto a rede digital precisa de cabos, conexões e antenas - isto é, transmissores físicos, nos quais se transfere a informação e ela é arquivada ou mantida - a forma ocidental de ensino precisou de tecnologias particulares para ser transferida através do globo: professores e treinamento de professores (algumas vezes ainda fisicamente, como aconteceu no século XIX ou ainda hoje), currículo escolar como uma forma institucional de organização e de classificação do conhecimento, livros escolares, móveis escolares e a arquitetura, painéis visuais nas salas de aula, uniformes, calendários e horários escolares, rotinas, discursos pedagógicos etc. Os estudos feitos sobre a disseminação das pedagogias de Lancaster e Pestalozzi mostraram os tradutores, os conectores e os viajantes que tornaram possível que estas teorias muito "locais" se tornassem métodos "universais", à uma escala mais ampla (ver Caruso \& Roldán, 2005; Tröhler, 2010; Horlacher, 2011).

Mas as tecnologias da escolarização não permaneceram as mesmas em viagem: a sua domesticação em práticas locais também significou serem traduzidas em outro 
conjunto de relações e atributos. E isso aconteceu a um custo: "uma coisa nunca pode ser totalmente traduzida para outro lugar ou tempo" e há sempre um preço a pagar "ao traduzir algo de um lugar para outro" (Latour et al, 2011, p. 28). É por isso que Mukhopadhyay e Sriprakash (2011) contestam o conceito de "empréstimo educacional", amplamente utilizado em estudos comparativos, que assume atores já definidos que se relacionam uns com os outros, e propõe, em contrapartida, estudar as traduções que configuram os agentes.

Os uniformes escolares materializam uma tecnologia escolar que permite também questionar as traduções. Eles surgiram em escolas para órfãos na Inglaterra e na França no século XVI como um sinal para distinguir as crianças pobres e sua dívida para com os seus apoiadores e financiadores, mas "viajou" para se tornar parte das escolas republicanas que inverteram o seu significado e os transformaram em uma tecnologia para disciplinar e homogeneizar o corpo do novo cidadão, aquele que deveria ser igual e idêntico aos outros, intercambiável, anónimo, mas também plebeu, austero, democrático. Ao estudar uniformes escolares em uma abordagem comparativa para a minha tese de doutorado, aprendi que os uniformes da Terceira República na França eram muito diferentes dos da Itália ou da Argentina: eram caseiros, todos de diferentes tecidos e cores, eram colocados sobre as roupas para protegê-las, e também em virtude de um discurso higiênico, como um meio de evitar que os germes e as bactérias alcançassem os corpos das crianças. Na Argentina, os uniformes eram batas brancas semelhantes às dos médicos, fabricadas industrialmente, e eram cuidadosamente e rigorosamente controlados pelas autoridades para ver se havia manchas ou furos, bem como eram investidos de significados morais, de saúde e políticos diferentes dos que os pedagogos franceses reivindicavam para os seus tabliers (Dussel, 2005).

Assim, a viagem desta tecnologia [uma Coisa em termos latourianos] transformouo, e o traduziu em um diferente conjunto de práticas. E a tradução não significa transportar as relações de causa e efeito, mas induzir à coexistência de dois mediadores (Latour, 2005, p. 108) - ou seja, colocar Coisas em relações diferentes. Este é o tipo de “rede de trabalho" que acredito que seria muito útil no estudo da escolarização em nível 
global e comparativo, para compreender os específicos transportes ou traduções que fizeram as escolas ficarem parecidas em alguns aspectos e tão diferentes em outros.

Neste ponto, também é hora de começar a questionar os panoramas sobre a disseminação das escolas e de tentar compreender esses mesmos panoramas como parte daquilo que precisa ser estudado. “O macro não é 'acima' nem 'abaixo' nas interações, mas acrescentado a elas como uma outra de suas conexões, alimentando-as e alimentando-se delas. Não há outra maneira conhecida para alcançar mudanças numa escala relativa" (Latour, 2005, p. 177). ${ }^{14}$ Nesta mudança de perspectiva, o estudo da escolarização tem muito a ganhar, evitando atalhos fornecidos por teorias gerais e tomando o longo caminho de seguir os traços como foi feito pela pesquisa "oligóptica". Mas seria prudente não esquecer que "todo este amontoado heterogêneo precisa ser reunido como uma ideia, um argumento, uma teoria" (Latour, 1995, p. 632). A busca seria para encontrar princípios de ordenação que dão espaço para ajuntamentos heterogêneos e produzem conceitos que ajudam os pesquisadores a "pensar sobre o que é ser mais do que um e menos do que muitos", como Mol e Law colocaram (2002, p. 11). A pesquisa, portanto, não deve estar confortável com a celebração de uma multiplicidade ilegível e a renúncia da teoria. A partir desta perspectiva, no estudo da escolarização não se deveria descartar a teoria, mas se deveria procurar uma teoria local fundada em estudos empíricos, que permita à pesquisa traçar as conexões sem aceitá-las inquestionavelmente.

\footnotetext{
${ }^{14}$ A teoria institucional global da propagação da escolarização (ver Ramírez, 2003), que eu não discuti neste artigo, pode ser lida através dessas lentes. Hoje é parte do panorama que dá forma a agentes (agências internacionais, professores universitários, agendas das revistas) e produziu novas conexões.
} 


\section{Referências}

ALEXANDER, Robin (2000) Culture and Pedagogy: international comparisons in primary education. London: Blackwell.

APPADURAI, Arjun (1996) Modernity at Large: cultural dimensions of globalization. Minneapolis: University of Minnesota Press.

BAQUERO, Ricardo, Frigerio, Graciela \& Diker, Gabriela (Eds) (2007) Las formas de lo escolar. Buenos Aires: Del Estante Editorial.

BEMSTEIN, Basil (1990) The Structuring of Pedagogic Discourse. Vol. IV: Class, Codes and Control. London: Routledge. http:// dx.doi.org/10.4324/9780203011263

BUISSON, Ferdinand (Ed.) (1887) Dictionnaire de pédagogie et d'instruction primaire, 4 vols. Paris: Hachette.

CARUSO, Marcelo \& ROLDÁN VERA, Eugenia (2005) Pluralizing Meanings: the monitorial system of education in latin america in the early nineteenth century, Paedagogica Historica, 41(6), 645-654. http://dx.doi.org/10.1080/00309230500336707

CHARTIER, Anne-Marie (1999) Un dispositif sans auteur: cahiers et classeurs dans l'école primaire,Hermès, 25, 207-218.

CHARTIER, Anne-Marie (2007) L'École et la Lecture Obligatoire: Histoire et Paradoxes des Pratiques d'Enseignement de la Lecture. Paris: Retz.

CHERVEL, André (1991) L' école, lieu de production d' une culture, in Analyser et gerer les situations d' enseignement-apprentissage. Actes du Sixiéme Colloque. Paris: Institut National de Recherche Pédagogique.

CHERVEL, André (1998) La culture scolaire. Une approche historique. Paris: Bélin.

COMPERE, Marie-Madeleine (ed.) (1997) Histoire du temps scolaire en Europe. Paris: INRPÉditions Éconornica.

DEPAEPE, Marc (2000) Order in Progress: everyday education practice in primary schoo/sBelgium, 1880-1970. Studia Paedagogica 29. Leuven: Leuven University Press. 
DEPAEPE, Marc e Karen Hulstaert (2013) Creating Cultural Hybridity by Exporting Metropolitan Structures and Cultures of Schooling and Educalisation? The Emergence of a Congolese 'Elite' in the 1950 s as a Starting Point for Further Research, European Educational Research Journal, 12 (1), 201-214.

DUSSEL, Inés (2005) When Appearances Are Not Deceptive: a comparative history of school uniforms in Argentina and the United States (19th-2oth centuries), Paedagogica Historica, XU(I \& II), 175-195.

ELKINS, James (2007) The Mottled Discourse of Chinese Studies, Art Bulletin, 89(3), 482486.

ESCOLANO BENITO, Agustín (2000) Las culturas escolares del siglo xx. Encuentros y desencuentros, Revista de Educación, Special Issue, 201-218.

FARIA FILHO, Luciano Mendes de, GONÇALVES, Irlen Aantonio, VIDAL, Diana Gonçalves \& PAULILO, André Luiz (2004) A cultura escolar como categoria de análise e como campo de investigação na história da educação brasileira, Educação e Pesquisa, 30(1), 139159. http://dx.doi.org/10.1590/S1517-97022004000100008

FENWICK, Tara \& EDWARDS, Richard (Eds) (2012) Researching Education through ActorNetwork Theory. Chichester: John Wiley \& Sons -

Blackwell. http://dx.doi.org/10.1002/9781118275825

GOMES, Ana Maria (2004) El proceso de escolarización de los Xakriabá: historia local y rumbos de la propuesta de educación escolar diferenciada, Cuadernos de Antropología Social, 19,29-48.

HAMILTON, David. (1989) Towards a Theory of Schooling. Lewes: Falmer Press.

HORLACHER, Rebekka (2011) 'Best Practice' around 1800. Johann Heinrich Pestalozzi's Educational Enterprise in Switzerland and the Establishment of Private Pestalozzi Schools Abroad, Encounters on Education, 12, 3-17.

HUNTER, Ian (1994) Rethinking the School: subjectivity, bureaucracy, criticism. Sydney: Allen \& Unwin.

JULIA, Dominique (1995) La culture scolaire comme objet historique, Paedagogica Historica, Supplementary Series, I, 353-382.

LAHIRE, Bernard (2008) La forme scolaire dans tous ses états, Revue suisse des sciences de l'éducation, 30(2), 229-258. 
LAKOFF, George \& JOHNSON, Mark (1980) Metaphors We Live By. Chicago: University of Chicago Press.

LATOUR, Bruno (1995) Joliot: history and physics mixed together, in Michel Serres (Ed.) History of Scientific Thought. London: Blackwell.

LATOUR, Bruno (2005) Reassembling the Social. Oxford: Oxford University Press.

LATOUR, Bruno (2010) Networks, Societies, Spheres: reflections of an actor-network theorist. Keynote speech at International Seminar on Network Theory: Network Multidimensionality in the Digital Age, Annenberg School of Communication, UCLA.

LATOUR, Bruno (2011) Some Experiments on Arts and Politics, E-Flux. http://eflux.com/joumal/view/217

LATOUR, Bruno, Harman, Geoffrey \& Erdélyi, Peter (2011) The Prince and the Wolf: Latour and Harman at the LSE. Winchester: Zero Books.

LAWN, Martin \& GROSVENOR, lan (2005) Introduction: the materiality of schooling, in M. Lawn \& L Grosvenor (Eds) Materialities of Schooling: design, technology, objects, routines. Oxford: Symposium Books.

MARTINIS, Pablo \& STEVENAZZI, Felipe (2008) Maestro comunitario: una forma de repensar lo escolar,Propuesta Educativa, 29, 59-7l.

MOL, Anne-Marie \& LAW, ]ohn (2002) Complexities: an introduction, in J. Law \& A. Mol (Eds) Complexities: social studies of knowledge practices. Durham, NC: Duke University Press.

MUKHOPADHYAY, Rarul \& SRIPRAKASH, Arathi (2011) Global Frameworks, Local Contingencies: policy translations and education development in India, Compare: A journal of Comparative and International Education, 41(3), 311-326.

NESPOR, Jan (1997) Tangled Up in School: politics, space, bodies, and signs in the educational process. Mahwah, NJ: Lawrence Erlbaum Associates.

NESPOR, Jan (2002) Networks and Contexts of Reform, Journal of Educational Change, 3 , 365-382. http://dx.doi.org/10.1023/A:1021281913741

NESPOR, Jan (2006) Technology and the Politics of Instruction. New York: Routledge. 
POPKEWITZ, Thomas (Ed.) (2005) Inventing the Modem Self and John Dewey: modernities and the traveling of pragmatism in education. New York: Palgrave Macrnillan.

http:// dx.doi.org/10.1057/9781403978417

POPKEWITZ, Thomas (2008) Cosmopolitanism and the Age of School Reform: science, education, and making society by making the child. New York: Routledge.

PROSSER, Jon (1999) The Evolution ofSchool Culture Research, in J. Prosser (Ed.) School Culture. London: Sage. http:// dx.doi.org/.4135/9781446219362.nl

RAMÍREZ, Francisco (2003) Comment: towards a global anthropology of the world? In K.M. Anderson-Levitt (Ed.) Local Meanings, Global Schooling: anthropology and world culture theory. New York: Palgrave MacMillan.

ROCKWELL, Elsie (2005) Walls, Fences and Keys: the enclosure of rural indigenous schools, in M. Lawn \& L Grosvenor (Eds) Materialities of Schooling: design, technology, objects, routines. Oxford: Symposium Books.

ROCKWELL, Elsie (2009) La experiencia etnográfica. Historia y cultura en los procesos educativos. Buenos Aires: Paidós.

ROCKWELL, Elsie (2012) Appropriating Written French: literacy practices in a Parisian elementary classroom, Reading Research Quarterly, 47(4), 382-403.

ROLDÁN VERA, Eugenia (2012) La escuela mexicana decimonónica como iniciación ceremonial a la ciudadanía: normas, catecismos y exámenes públicos, in A. Acevedo Rodrigo \& P. López Caballero (Eds) Ciudadanos inesperados: espacios de formación de la ciudadanía ayer y hoy. Mexico: El Colegio de México DIE/CINVESTAV.

SEIWYN, N. (2011) Schools and Schooling the Digital Age. London: Routledge.

SOUTHWELL, Myriam (2011) La educación secundaria en Argentina. Notas sobre la historia de un formato, in G. Tiramonti (Ed.) Variaciones sobre la forma escolar. Límites y posibilidades de la escuela media. Rosario, Argentina: Homo Sapiens.

STOLL, Louise (1999) School Culture: black hole or fertile garden for school improvement? In J. Prosser (Ed.) School Culture. London: Sage. http://dx.doi.org/10.4135/9781446219362.n3

SYMES, Colin \& MEADMORE, Daphne (Eds) (1999) The Extra-ordinary School: parergonaHty and pedagogy.New York: Peter Lang. 
TRÕHLER, Daniel (2010) L'offre et la demande: la Méthode de Pestalozzi dans le contexte européen. Johann Heinrich Pestalozzi, in Ecrits sur la Méthode, vol. III - Esprit de la Méthode. Le Mont-sur-Lausanne: LEP Editions.

TYACK, David \& CUBAN, Larry (1995) Tinkering toward Utopia: a century of public school reform. Cambridge, MA: Harvard University Press.

VIDAL, Diana Gonçalves (2005) Culturas escolares: estudo sobre práticas de leitura e escrita na escola pública primária (Brasil e França, final do século XIX). Campinas, Brasil: Autores Associados.

VIÑAO FRAGO, Antonio (2002) Sistemas educativos, culturas escolares y reformas. Madrid: Morata.

VINCENT, Guy, LAHIRE, Bemard \& THIN, Daniel (1994) Sur I'histoire et théorie de la forme scolaire, in Guy Vincent (Ed.) L'éducation, prisonniere de la forme scolaire. Scolarisation et socialisation dans les societés industrielles. Lyon: Presses Universitaires de Lyon.

WEXLER, Philip (1994/1995) Neither Sacred nor Profane. Symposium: goveming the school, Arena Journal, 4, 161-170.

WILLIARNS, Raymond (1977). Marxism and Literature. Oxford: Oxford University Press.

Recebido em: 21/10/2013 Aprovado em: 25/03/2014

Universidade do Estado de Santa Catarina - UDESC Programa de Pós-Graduação em Educação - PPGE

Revista Linhas

Volume 15 - Número 28 - Ano 2014 revistalinhas@gmail.com 